\title{
The Principles of Ecopath with Ecosim and its Application in Marine Ecosystem
}

\author{
Yashu Bai ${ }^{a}$, Rongshuo Cai ${ }^{b}$ \\ Third Institute of Oceanography, State Oceanic Administration People's Republic of China, Xiamen, \\ Fujian, China \\ abaiyashu@tio.org.cn, bcairongshuo@tio.org.cn
}

Keywords: EwE, Ecospace, Ecosystem model

Abstract. Ecopath with Ecosim(EwE)is the core tool of simulating aquatic ecosystem and originated from Ecopath model. The paper reviewed the principle of EwE and its application in the structure and trophodynamics characters of marine ecosystem, fishery management, marine pollution and set of marine protected areas as well as the progress and perspectives in China. The Ewe has powerful simulation and analysis function and the data for EwE modelling are relatively simple; therefore, it has large potentials for application and development in China.

\section{Introduction}

Ecopath with Ecosim (EwE) is derived from the Ecopath model by continuous development and improvement of ICLARM and UBC. It has become a powerful simulation tool for aquatic ecosystems, and has been applied widely to and validated all over the world in ecosystem studies in different latitudes and of different types [1]. Due to the influence of rapid development of coastal economics and climate change, the health of China's coastal marine ecosystems and sustainable development of biological resources are under threat with ecosystem structure continuously being destroyed. It is an urgent issue to analyze in-depth the food web structure and energy flow characteristics in China's coastal marine ecosystem for establishing a scientific and rational management system. In this article, we review and discuss the functions and use of the tools in the EwE models in hoping that the ecological system analysis tool can be further utilized and applied to the studies and management of marine ecosystems in China.

\section{Principle of EWE}

The Ecopath module. Ecopath module is to simulate the biological compositions and energy flows between the biological communities using homogeneous linear equation, where important ecological parameters, such as biomass, amounts of production and consumption, nutritional conversion in the ecosystem are determined based on the law of conservation of energy. The simplified food web model constructed by Ecopath focus on the study of ecological interaction and can reflect the energy flow in the food web and biomass, and the process and results of biomass production.

The Ecosim module. Ecosim is an analysis module for temporal and spatial dynamics of the ecological parameters on top of the Ecopath model. The energy dynamic model in the module can be used to simulate and analyze the temporal dynamics in the whole system or in relevant systems by setting up various scenarios under artificial or natural inferences and inputting the quantified parameters under these scenarios into the models.

The Ecospace module. Ecospace uses parameters calculated from the Ecopath model with the Ecosim model. It enhances the process parameters of spatial dynamic changes in the ecosystem and can be used to show the spatial flow of energy in food webs in the ecosystem. Ecospace model is a spatial module for Ecosim. It can allocate biomass dynamically onto to background spatial grid map, and determine if the grid is a "suitable habitat" by defining the predation risk and feeding rate of given functional groups in the grid[2]. Ecospace allows users to enter information about habitat, catching and protection of relevant functional groups for spatial analysis [3]. 


\section{The Major Applications of EWE in Marine Ecosystems}

Ecological system structure and nutrition dynamics. The dynamics researches on the components and their interactions, internal hierarchy structure in ecosystem, the relationship between the ecosystem structure and their stability and the nutrition dynamics in food web have been always hot topics in marine ecology and are the prerequisites for environment and fishery management (Song et al., 2007). Using the Ecopath module, the structure and nutrition dynamics of the ecosystem can be quantified and analyzed. Tremendous basic research has been carried out since the last century. For example, Arreguín-Sánchez \& Manickchand-Heileman used the Ecopath to evaluate the trophic role of snappers on the continental shelves of the south-western Gulf of Mexico and the Yucatan in the south-eastern Gulf of Mexico, which shows in Table 1. They compared the stability of the ecosystems in terms of persistence, recovery time and resilience. The western Gulf of Mexico system appeared more complex and more stable than the Continental Shelf of Yucatan. Correlation of stability attributes between groups suggested differences in the role of snappers between the ecosystems suggesting that each stock should be managed individually [4]. Vega-Cendejas \& Arreguin-Sanchez applied the Ecopath to mangrove ecosystem in the Gulf of Mexico, and found that about $60 \%$ of the energy is transferred from debris to micro crustaceans and then to a variety of fish larvae, suggesting that the debris is important in the system, while fish has lower eco-nutrition efficiency, indicating that they are seldom predated. Mangrove ecosystems are shown to be excellent habitat and foraging sites for larvae of many economic fish and are therefore important to maintain and protect the system for better conservation of fishery resources [5].

Table 1. Diet composition and mortality caused by snappers on prey groups in the Western Gulf of Mexico and the north continental shelf of Yucatan ecosystems as computed [4]

\begin{tabular}{lcc}
\hline Prey & Proportion in diet & Mortality caused \\
\hline WGM & & \\
Mojarra: erreidae & 0.455 & 0.76 \\
Seatrout: Sciaeridae & 0.004 & 0.18 \\
Grunts: Haemulidae & 0.155 & 0.15 \\
Other fish & 0.353 & 0.07 \\
Zooplankton & 0.006 & 0.01 \\
Benthic prod. & 0.027 & 0.01 \\
CSY & & \\
Grunts:Haemulidae & 0.144 & 0.1 \\
Herrings: Clupeidae & 0.112 & 0.15 \\
Mojarra & 0.404 & 0.48 \\
Seatrout: Sciaeridae & 0.004 & 0.26 \\
Shrimp: Panaeidae & 0.034 & 0.03 \\
Lobster: Palinuridae & 0.053 & 0.06 \\
Crabs: Portunidae & 0.053 & 0.04 \\
Octopus: O. maya & 0.187 & 0.15 \\
Zooplankton & 0.009 & - \\
\hline
\end{tabular}

Impacts of fishery on marine ecosystem. Fishery is one of the most influential human activities on aquatic ecological systems. Due to continuous and selective removal of the top predator during fishery processes, the predation pressure is reduced and the top-down effect is dramatic on the structure of ecosystem. The Ecosim module can dynamically simulate the influence of fishery policy and environmental disturbance on the production and the amount of the resource in a certain period of time. Pauly et al summarized the results from over 60 studies based on the Ecopath model, and showed that the global mean trophic level of the fisheries landings decreased from slightly more than 3.3 in the early 1950s to less than 3.1 in 1994 (Fig. 1). The reason is that with increase of fishing pressure, the catches gradually change from carnivorous, demersal fish of long-life time to pelagic 
fish of plankton feeding and short-life time. Correspondingly, the fishing yield was first increased and then reduced, suggesting that the global fishery resources have been over-exploited and the development is not sustainable [6].

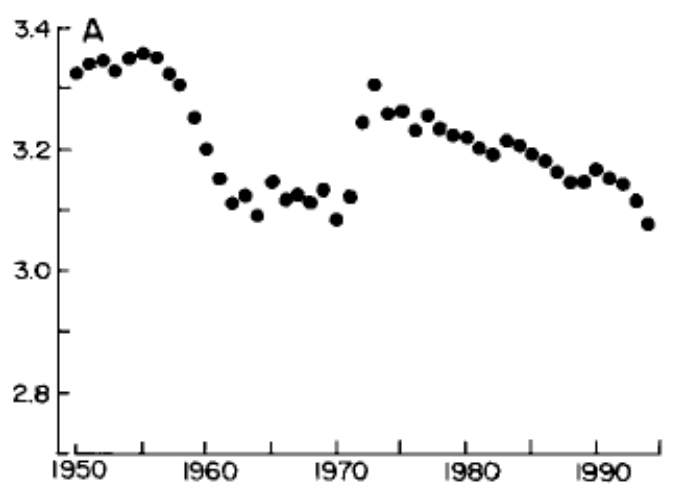

Figure 1. Global trends of mean trophic level of fisheries landings in Marine areas, 1950 to 1994[6]

In addition, by iterative simulation, the Ecosim model can produce for time-series data suitable for prediction of biomass per unit. The data can be used for suitability study on fisheries and environmental impact [7]. For example, Christensen used the Ecosim to simulate and study how to recover the biological resources by reducing fishing pressure [8]. Kitchell et al applied EwE to Lake Superior in Canada. They simulatied and analyzed the response of the ecological system to management policy under recreational fishery and alien species invasion conditions and recovery strategy for local trout populations [9].

Impact of environmental pollution on marine ecosystem. By comparing the structure of the ecosystem and biomass of key species before and after the disturbance, the influence of the environmental disturbance can be evaluated quantitatively. Researchers in the Fisheries Research Center at Columbia University in Canada have applied the Ecopath model to study the impact of the 1989 Exxon Valdez spill over the Prince William Bay ecosystem [10].

In addition, the Ecopath model can be used together with other ecological and toxicological models for better analysis of the distribution, accumulation and transport of poisons in the ecosystem. For example, Career et al developed an Ecopath model for shallow water area in north of the Venice lagoon. In the model, metabolic rate, food composition and structural characteristics were inputted as another eco toxicological input parameters and the biological accumulation of dioxins in various aquatic organisms was successfully evaluated [11].

Setting up marine protected areas. Under the given system structures, users can use the Ecospace model as a tool for exploring potential marine protected areas (MPAs). Ecospace Scenario Stimulation can analyze spatial flow of the food web between different trophic levels to predict spatial distribution and change of migration rate, habitat suitability degree and biomass in different functional groups as well as spatial distribution and change of the fishing effort. This would be useful for assessment of the benefits of MPAs for better MPA setting up [2].

\section{Application of EWE in Coastal Areas of China}

Tong \& Tang developed the first preliminary channel of energy flow in China based on the survey data obtained in the Bohai Sea from 1982 to 1983 [12]. In recent years, Wang, Chen, Liu, and Li, constructed Ecopath models for the Dayawan, the northern Gulf and the South China Sea continental shelf, respectively $[13,14,15,16,17]$. In addition, Jiang et al developed the dynamic Ecosim models for Sea marine ecosystems in northern continental shelf of South China Sea [18]. Chen et al and Feng et al analyzed the impact of fishing on marine ecosystem in Beibu Gulf and Bohai Bay using Ecosim[19,20,21]. Jiang \& Cheng constructed an Ecospace model for marine ecosystems in the East China Sea to analyze the economic and ecological benefits of protecting the existing fishery protection areas, and showed that protection of East China Sea Fisheries will generally benefit the 
fishery industry advantage, but, there are cost-benefit tradeoffs and game between various fishery industry sectors [22].

\section{Conclusions and Prospect}

At present, the EwE tools are mainly used in the South China Sea and the East China Sea regions. Most of studies conducted in China are at initial stage of Ecopath model construction, and the Ecosim and Ecopace modules are seldom used. China has a vast sea area with abundant species. Long-term investigations and researches have been done along the coastal waters from North to South, and have accumulated huge amount of basic data for many years. However, the study on the entire marine ecosystems is lacking, and most of the works are at the level of the population and community, and little has been done on the the nutrition structure and basic function of the whole ecosystems.

The Ewe has powerful simulation and analysis function and has been widely used in other countries for different regions of the harbors and shelf waters. It has been proven to be an effective and quantitative tool for marine ecosystem study and management. In comparison with the other model software, the data for EwE model are relatively simple. The software can use very conveniently the traditional resources, ecological investigation and historical literature data; therefore, it has large potentials for application and development in China. We hope that a multidisciplinary team consisting of ecologists, biologists, personals from relevant government departments can be set up for long-term collaborative investigation, monitoring and data gathering to use EwE for ecosystem -wide analysis of impact of fishery and pollution on marine ecosystem. A macro level, quantitative and objects-oriented of management and decision-making system can then be established to provide strong and scientific support for management and sustainable development of marine ecosystems in China.

\section{References}

[1] Walters Carl, Pauly Daniel, Christensen Villy and et al. Representing density dependent consequences of life history strategies in aquatic ecosystems. Ecosim II. Ecosystems Vol.3 (2000), p. 70-83.

[2] Li Na, Cheng Heqin, Jiang Hong. Application of Ecospace Model in Evaluating Marine Protected Areas. World Sci-tech Research and Develop Vol.30 (2008), p. 723-727.

[3] Song Bing, Chen Liqiao, Chen Yong. An application of Ecopath with Ecosim to aquatic ecology. Marine Science Vol.31(2007), p. 83-86.

[4] Arreguín-Sánchez F \& Manickchand-Heileman S. The trophic role of lutjanid fish and impacts of their fisheries in two ecosystems in the Gulf of Mexico. Journal of Fish Biology, 53 (1998), p. 143-153.

[5] Vega-Cendejas M E, Arreguin-Sanchez E. Energy fluxes in a mangrove ecosystem from a coastal lagoon in Yucatan Peninsula, Mexico. Ecology Modelling, 137(2001), p. 119-133.

[6] Pauly D, Christensen V, Dalsgaard J. 1998. Fishing down marine food webs. Science, 279 (1998), p. $860-863$.

[7] Yue Tianxiang: Resource and Environment Mathematical Model Manual. (Science Press, Beijing 2003).

[8] Christensen V. 1998. Fishery-induced changes in a marine ecosystem: insight from models of the Gulf of Thailand. Journal of Fish Biology, 53 (1998), p. 128-142.

[9] Kitchell J F, Cox S P, Harvey C J,et al. Sustainability of the lake superior fish community: interactions in a food web context. Ecosystems, 3(2000), p. 545-560. 
[10] Tong Ling. Ecopath model-a mass-balance modeling for ecosystem estimation. Marine fisheries research, 20(1999), p. 103-107.

[11] Carrer S, Halling-Sorensen B, Bendoricchio G. Modelling the fate of dioxins in a trophic network by coupling an ecotoxicological and an Ecopath model. Ecology Modelling, 126(2000), p. 201-223.

[12] Tong L, Tang Q S and Daniel Pauly. A preliminary approach on mass-balance ecopath model of the Bohai Sea. Chinese Journal of Applied Ecology, 11(2000), p. 435-440.

[13] Wang Xuehui, Du Feiyan, Qiu Yongsong and et al. Study on the ecosystem model of Daya Bay I: A preliminary approach on energy flow model. South China Fisheries Science. 1(2005), p. 1-8.

[14] Chen Zuozhi, Qiu Yongsong, Jia Xiaoping. Mass-balance ecopath model of Beibu Gulf ecosystem. Chinese Journal of Applied Ecology, 17(2006), p. 1107-1111.

[15] Chen Zuozhi, Qiu Yongsong, Jia Xiaoping and et al. Structure and function of Beibu Gulf ecosystem based on Ecopath Model. Journal of Fishery Sciences of China, 15(2008), p. 461-468.

[16] Liu Yu, Jiang Tao, Wang Xiaohong and et al. Establish and analysis of the Ecopath model of the ecosystem in the Northern Continental Shelf of South China Sea. Acta Scientiarum Naturalium Universitatis Sunyatseni, 45(2007), p. 123-127.

[17] Li Rui, Han Zhen, Cheng HeQin and et al. A Preliminary Study on Biological Resources Energy Flows Based on the ECOPATH Model in the East China Sea. Resources science, 32(2010), p. 600-605.

[18] Jiang Tao, Liu Yu, Li Shiyu and et al. Simulation of the Time Dynamics of Marine Ecosystems in the Northern Continental Shelf of South China Sea with Ecosim Model. Acta Scientiarum Naturalium Universitatis Sunyatseni, 46(2007), p. 108-112.

[19] Chen Zuozhi, Qiu Yongsong, Jia Xiaoping. An evaluation of the fisheries management strategies in Beibu Gulf: using Ecopath with Ecosim. Acta Ecologica Sinica, 27(2007), p. 2334-2341.

[20] Chen Zuozhi, Qiu Yongsong, Jia Xiaoping and et al. Effects of fishing on the marine ecosystem of Beibu Gulf. Chinese Journal of Applied Ecology, 19(2008), p. 1604-1640.

[21] Feng Jianfeng, Zhu Lin, Wang Hongli. Study on characters of coastal ecosystem in Bohai Bay with EwE. Marine Environmental Science, 29(2010), p. 781-784.

[22] Jiang Hong, Cheng heqin: Situations on the East China Sea Fishery ecosystem and marine protected areas scenarios(East China Normal University, Shanghai 2008). 